\section{EXPERIÊNCIAS PRECURSORAS DO TURISMO ECOLÓGICO NO BRASIL: Um Depoimento Pessoal}

\author{
Domingos de Toledo Piza*
}

RESUMO: Ahorda as possibilidades da intermediaçāo dos serviços turísticos para o desenvolvimento do "Estudo do Meio", com base na experiência de mais de trinta anos na área. Explica os objetivos e fases na operacionalização dessa proposta e comenta cinco roteiros, ressaltando o Roteiro da Amazônia. Os profissionais de Turismo devem integrar equipes que visem a realizaçāo dessas viagens, a fim de tornar mais eficaz e produtivo o "Estudo do Meio". Assinala, também, a im portância desse processo para a formaçāo do cidadāo brasileiro, si tuando-o como complemento indispensável à formaçāo educacional de nossos jovens e crianças.

PALAVRAS CHAVE: Turismo: roteiros ecológicos. Estudo do meio: serviços turísticos.

ABSTRACT: Describes pioneer experiences of ccologic tourism in Brazil, since the intennediation of touristic senvices for the development of the "environment study,", based on the perfonnance of more than 30 years in this area. It explains the objectives and phases turning this proposal ope rational and comments 5 different packages, emphasizing the one for Amazon. Tourism professionals inust integrate teams which visualize the realization of these trips, in order to turn more efficient and productive the "environment study". It also shows out the importance of this process in the formation of brazilian citizen, siting him as an indispensable com plement in the education formation.

KEY WORDS: Tourism: ccologic packages. Emironment studv: touristic senices.

(*) Licenciado em Filosofia pela Faculdade de Filosofia. Letras e Ciências Humanas da USP. Bacharel em Direito pela Faculdade de Direito da USP. Profissional de Relaçōes Públicas registrado. Diretor Presidente da Toledo Piza Empreendimentos Turísticos Lida.

End. para corresp.: Rua Capitāo Francisco Padilha, 112 - CEP 01448 - Sāo Paulo SP - Brasil.

\section{INTRODUÇÃO}

De início, em 1947, apenas nossa formação em Filosofia pela Universidade de São Paulo, com Didática em Licenciatura. Do magistério exercido desde 1948 nas escolas públicas, culminamos nossa experiência pedagógica no Instituto Caetano de Campos, escola padrão na época, como professor de Pedagogia, Filosofia da Educação e História da Educação.

Dos seis anos de magistério, restou-nos uma cabeça repleta de idéias dos grandes educadores, sendo que, na prática, apenas conseguimos realizar algumas atividades extra-classe de meio período para visitas a locais de interesse pedagógico. Não havia nada planejado ou preparado para que o aluno vivenciasse uma realidade fora da escola mediante uma programação dirigida.

Em 1960, realizando um trabalho de atendimento aos passageiros da Real Aerovias, assumimos o cargo de "public relations". Dois anos mais tarde, em 1962, a VARIG comprou a Real Aerovias. Sabíamos que se não apresentássemos algo de novo que interessasse à Companhia, nosso cargo seria preenchido por um funcionário da mesma.

Nessa época, os colégios mais elitizados de São Paulo - Santa Cruz, Sion, Assunção, Dex Oiseaux - reuniram-se em um Seminário preparatório do "curriculum" da Escola Nova a ser aplicado em 1963. $\mathrm{Na}$ ocasiāo, pedimos 15 minutos para apresentar o processo educativo "Estudo do Meio" aos participantes. Apresentamos o processo para mais de 30 professores, oferecendo possibilidades de viagens tendo os serviços da VARIG como transportadora e os nossos como responsáveis pela operacionalização da mesma. Ao final, imediatamente o Colégio Sion solicitou-nos um programa, tendo como centro de interesse Minas - Cidades Históricas.

Iniciaram-se, assim, os primeiros roteiros sistematizados sob o enfoque do "Estudo do Meio", no mercado de viagens do Brasil.

Neste artigo abordamos, inicialmente, a operacionalização da nossa proposta, passando, depois à descrição de cinco roteiros de viagens - tudo na forma de um depoimento pessoal com base na experiência junto a escolas de $\mathrm{r}^{\circ}$. e $2^{\circ}$ grau de São Paulo. Finalmente, discutimos a importância dos serviços turísticos nesse processo e a importância deste na educação dos brasileiros. 


\section{OPERACIONALIZAÇÃo DA PROPOSTA}

\subsection{Da experiência empírica à experimental}

Para a realização do programa Minas - Cidades Históricas, mais empirismo: não conhecíamos Belo Horizonte e muito menos as Cidades Históricas. Munidos de cartas de apresentação da VARIG ao Governador do Estado e Prefeito de Belo Horizonte, viajamos para aquela cidade. Ambos colocaram pessoal a nossa nossa disposição, mostrando o que havia de melhor na região. Isto permitiu-nos locar o transporte terrestre, contratar hospedagem, restaurantes e guias locais, além de cronometrar visitas e passeios, enfim, elaborar o roteiro final da viagem.

Surgiu, assim, o primeiro roteiro sistematizado de "Estudo do Meio", tendo por centro de interesse Minas - Cidades Históricas. E foi portanto através de uma Companhia Aérea e não de uma Secretaria de Educação que se lançou esse roteiro, como atesta telegrama de 14 de maio de 1962, dirigido ao então diretor daquela Companhia, Oscar Siebel:

Acuso recebimento carta 3 do corrente, que me comunica inicio excursoes culturais. Terei maior satisfaçäo receber excursionistas. Valho-me ensejo para cumprimentar essa empresa pela interessante iniciativa.

essa empresa pela interessante iniciativa.
José Magalhães Pinto - Governador de Minas Gerais.

Além do Colégio Sion, o Santa Cruz e o Dex Oiseaux realizaram o roteiro a Minas em 1962. No ano seguinte, o Dex Oiseaux solicitou um roteiro ao Nordeste, abrangendo as seguintes cidades: Fortaleza, Recife, João Pessoa, Salvador e Paulo Afonso. Providências iguais foram tomadas e mais um roteiro desenvolvido.

Com o propósito de divulgar e operacionalizar tais roteiros junto aos colégios da cidade de São Paulo, formamos um grupo envolvendo profissionais de turismo, professores, líderes e universitários. Em 1963 editamos um folheto intitulado "Estudo do Meio" - Programas de Viagem, especialmente preparados para serem usados como processo pedagógico pelos colégios de São Paulo. Em 1973, publicamos um segundo folheto já incluindo o "modus fasciendi" da operacionalização do processo, tanto no campo do conhecimento quanto no das atitudes. Nesses dois casos, os roteiros eram passíveis de adaptação mediante o centro de interesse escolhido e a orientação pedagógica de cada colégio.

\subsection{Objetivos e Fases}

Antes da viagem o aluno recebe um folheto, contendo informações básicas sobre o processo, programa da viagem e avisos gerais. Essas informações são discutidas com todos os participantes: alunos, professores e guias. Os objetivos do processo são os seguintes:

a) colocar o aluno em condições reais, levando-o aos locais a fim de lhe possibilitar uma observação direta e vivenciada da realidade;

b) levar o aluno a compreender que se trata de uma atividade fora da sala de aula, mas nela se inicia e termina, mantendo sempre a preocupaçăo básica ensino-aprendizagem;

c) levar o aluno a perceber como o contato com a realidade facilita a compreensão e incorporação da mesma, desde que tenha sido preparado para a adequada observação dos fatos.

O processo desenvolve-se em três fases, como descrito a seguir.

\subsubsection{Primeira Fase}

Na primeira fazemos a escolha e o preparo teórico do centro de interesse, relacionado ao roteiro de viagem. Os professores das diversas disciplinas envolvidas ministram o conteúdo necessário, inserido em um plano integrado de ensino preestabelecid(

\subsubsection{Segunda Fase}

É a realização da viagem, fase em que a documentação dos dados observados são anotados ou gravados na forma de entrevistas, fotografias, filmagens, além da coleta de material representativo para apresentação durante a fase seguinte.

Assim, quanto à História, interessam os monumentos históricos: no campo da Geografia, o relevo, a vegetação, o clima, a população, os meios de comunicação e atividades econômicas; quanto ao aspecto humano, o tipo físico dos habitantes, os costumes, a produtividade e o nível de vida (saúde, habitação, trabalho, alimentação e lazer).

No campo do conhecimento, o aluno tem oportunidade de incorporar o processo civilizatório, compreendendo que a resposta do homem ao meio ambiente varia nos diversos momentos históricos. De vemos considerar o homem no espaço e no tempo e sua relação com a natureza e com o próprio homem. 
Para que isso aconteça é importante que o aluno interaja com os colegas, professores e guias, comunidades e locais visitados, adquirindo conhecimentos a partir de situaçōes novas. Todos os participantes são responsáveis pelo êxito da viagem. Para os alunos, os professores e guias estão presentes na forma de coordenadores do processo, ajudando, orientando e estimulando-os a atingir os objetivos propostos.

Ainda nesta fase, colocamos a questão das atitudes, como por exemplo:

a) nos ônibus: higiene nos banheiros; respeito ao motorista; não colocar a cabeça e os braços fora da janela; respeito aos transeuntes; não jogar papéis e alimentos pela janela; atender às normas de embarque e desembarque ;

b) nos hotéis: atitude de respeito desde a recepção, leitura do regulamento, atendimento aos horários de silêncio, manutenção da ordem nos quartos e respeito pelos outros hóspedes;

c) nos restaurantes: servir-se do quanto quizer, nunca a mais do que pode comer;

d) nos lugares públicos: manter o interesse e respeito pelos hábitos e costumes da região visitada.

\subsubsection{Terceira Fase}

Esta é a fase da avaliação. Durante a reali/ação da viagem, diariamente, à noite e por cerca de 15 minutos promovemos um "batepapo" informal. Com isso podemos averiguar se o trabalho dos professores e guias foi realmente profícuo, provocando uma mudança no comportamento dos alunos, a nível de conhecimento e atitudes. Ainda, nesta atividade extra-classe, desenvolve-se, no aluno, sua capacidade de raciocínio, memorização e comprensão, expressão verbal e escrita, relacionamento e trabalho de grupo.

Mas a avaliação não termina aqui. Após a viagem, já em classe, o aluno será avaliado de diversas formas: trabalhos em grupo, dramatização de situaçōes, conclusōes individuais, exposição de material coletado, apresentação de fotos e slides, e outras manifestaçōes criativas sobre a experiência vivida. Pelo grau de qualidade desses trabalhos avaliamos também o trabalho dos professores e guias, e, conseqüentemente, a eficácia da própria viagem.

\section{EXPERIÊNCIAS PRECURSORAS DO TURISMO ECOLÓGICO NO BRASIL?}

Os roteiros que comentamos neste item traduzem as primeiras experiências a partir do "Estudo do Meio", que aliaram, a nosso ver, o Turismo ao Meio Ambiente com função pedagógica. Foram, na verdade, os primeiros roteiros sistematizados e com "preocupação ecológica" a serem veiculados no mercado de viagens do Brasil, dirigidos a um público estudantil de colégios tradicionais e elitizados da cidade de São Paulo.

Do elenco de 68 roteiros já citados, selecionamos cinco, sendo que o último deles - Roteiro da Amazônia - é discutido mais detalhadamente, pois foi um dos mais aprimorados durante toda a nossa experiência.*

\subsection{Roteiros Cidades Históricas de Minas, Nordeste, \\ Foz do Iguaçu e Tietê}

Em 1962, o Colégio Santa Cruz solicitou-nos o roteiro Minas Cidades Históricas, no qual um dos pontos principais era a mineração. Programamos uma visita à Belgo-Mineira com sua mineração a céu aberto. Durante essa visita, ressaltamos os benefícios da utilização do minério e seus manufaturados; em contraposição, alertávamos sobre os cuidados a serem tomados para minimizar as consequências da devastação das matas e montanhas de ferro, da modificação do relevo, da poluição e diminuição do volume de água dos rios, como era o caso do Rio das Velhas (Sabará - MG), antes navegável e na época um pequeno riacho. Queríamos que o aluno compreendesse que tais locais aproveitados economicamente deveriam agredir o mínimo o ecossistema envolvido.

Em 1963, com esse mesmo colégio, realizamos o Roteiro do Nordeste, tendo como um dos pontos principais o Polígono da Seca. Para chegarmos ao Açude de Pentecostes (Pentecostes - CE), passamos por zonas de carnaubais e caatingas, atravessamos estradas com pontes sobre rios secos. Na paisagem então seca da caatinga, pudemos avista uma região verde com produção de frutas cítricas irrigada artificial-

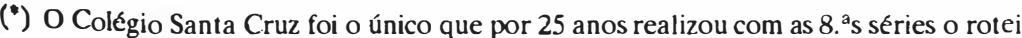
ro Minas - Cidades Históricas, cujo "Estudo do Meio" nele envolvido era orientado por Samuel Franco, professor de geografia e diretor pedagógico do $10^{\circ}$ grau. Esse colégio realizou, também, por mais de 10 anos consecutivos o Roteiro da Amazônia. 
mente. Terminamos o passeio com um banho de piscina em pleno Polígono da Seca. Procurávamos mostrar que as condições do Nordeste podem ser modificadas favoravelmente pela ação do homem, de maneira a transformar a região em uma das mais produtivas do País. Mas, mostrávamos, também, que na maioria das vezes a ação do homem não era racional: o engenheiro do DNOCS* que nos acompanhou na visita ao açude informou que sua água estava salobra por falta de cuidados necessários na escolha do local, a qual havia sido norteada por razões políticas e não geológicas; isto dificultava o total aproveitamento do mesmo e de todo o sistema de irrigação artificial.

Um outro roteiro muito procurado foi o de Foz do Iguaçu, no qual destacamos a ação do homem sobre a natureza com a construção de Itaipu. Nessa construção, as Cataratas de Iguaçu foram preservadas, mas o mesmo não ocorreu com as Sete Quedas que submergiram no grande lago formado pela barragem. Na época, os problemas da fauna e flora foram amenizados com pessoal especializado salvando animais antes do fechamento das comportas. Ao lado do benefício e progresso que a maior hidrelétrica do mundo nos trouxe, muita coisa foi sacrificada - paisagem, clima, fauna, flora e o próprio homem.

Outro ponto interessante era levar o aluno que vive em São Paulo para conhecer o rio Tietê totalmente poluído na cidade e, depois, conhecê-lo a partir de Piracicaba, com suas águas claras e piscosas, chegando a atingir até sete quilômetros de largura.

\subsection{Roteiro da Amazónia}

O Roteiro da Amazônia, incluindo Belém, Santarém e Manaus, foi aperfeiçoado durante dez anos consecutivos, sem interrupção, visando a aplicação do "Estudo do Meio" de forma organizada, considerando as suas três fases já descritas.

O professor Samuel Franco envolvido nesse processo desenvolvia em classe por três meses o seguinte tema: "Para se Compreender a Amazônia, Temos que Compreender o Binômio Rio-Floresta”. Nessa fase, cada aluno tinha um caderno - o Caderno da Amazônia - onde anotava todos os dados por ele apreendidos. A idéia era a de provocar nele uma conscientização dos problemas da Amazônia. Fazia parte desse aprendizado temas na época atuais e polêmicos, tais como:

(*) DNOCS: Departamento Nacional de Obras Contra a Seca. a) desmatamento/reflorestamento;

b) Amazônia, "pulmão do mundo";

c) Amazônia, "celeiro do mundo";

d) importância da manutenção do equilíbrio ecológico na exploração das riquezas minerais;

e) exploração da seringueira, do cacau e da madeira;

f) "modus vivendi" do manauara* dentro do complexo rio-floresta;

g) meios de transporte e comunicação.**

Embasados da teoria, saímos a campo, em uma viagem de dez dias de duração (segunda fase do processo).

Em Belém, no Museu Goeldi, conhecemos as coleções de exemplares da flora e fauna amazônica e coleções arqueológicas resultantes de escavações na Ilha de Marajó e região do Baixo Amazonas.

Em um passeio de barco pelos furos igarapés e igapós, pudemos apreciar as vitórias-régia. Caminhando pela floresta, passamos por pequenas plantações de cacau e seringueiras. Visitando uma escola, em plena floresta, soubemos que a professora ministrava aula há cinquenta anos para as quatro séries do primário ao mesmo tempo. Os alunos chegavam à escola em uma piroga, debaixo, muitas vezes, de muita chuva e a velha mestra tinha uma roupa seca para cada um. Ao acabar a aula, ele vestia novamente a sua roupa molhada para voltar para casa. Vimos, ainda, uma enorme aranha no teto "fazendo parte do ecossistema" - os alunos não se perturbavam, pois sabiam que a aranha não era venenosa.

Em Santarém, realizamos um passeio de barco pelo rio Tapajós até o povoado de Alter do Chão*** com suas praias de areia branca. Nosso almoço foi servido na floresta à beira da praia.

O encontro do rio Tapajós com o Amazonas deu-nos uma clara visão do binômio rio-floresta, e pudemos observar as populações ribeirinhas vivendo em palafitas. Adentrando em uma delas, informaram-nos que quando o rio subia muito e não havia mais condições de

(*) Manauara: habitante de Manaus.

(*) Esses temas eram analisados a partir de livros, como os seguintes: "A Selva", de Ferreira de Castro; "O Seringal e o Seringueiro", de Artur Cesar Ferreira Reis: "Brasil - Terra de Contrastes", de Roger Bastide.

$\left({ }^{* * *}\right)$ Atualmente, esse local é muito procurado por turistas estrangeiros que visitam a Amazónia. 
habitá-la, os seus moradores mudavam para a do vizinho mais próximo, que estivesse em uma posição mais alta. No entanto, após a enchente, retornavam à sua habitação com tudo o que havia sobrado, como as marombas com gado.ou as pequenas plantaçōes de legumes e verduras.

Em Manaus presenciamos o Encontro das Águas do rio Negro com o rio Solimōes, formando o Amazonas. Informaram-nos da existência de uma pesquisa realizada por estudiosos franceses sobre o aproveitamento da energia resultante desse encontro, que poderia ser aproveitada com grandes benefícios para a regiāo.

$\mathrm{Na}$ travessia do rio Negro, explicaram-nos porque os peixes desse rio não têm escamas e porque inexistem insetos como mosquitos e pernilongos - esse rio é rico em enzimas.

Em outro passeio de barco pelo Igarapé do Guedes, fizemos uma caminhada na selva apreciando a fauna e flora exóticas, e tomamos banho de igarapé, além de saborear uma peixada típica em restaurante flutuante no meio da floresta.

Visitando a região do porto flutuante e do mercado com sua magnífica construção de ferro, ficamos sabendo da existência da antiga cidade flutuante, com mais de 2.000 habitantes que viviam em barcas com grande promiscuidade e falta de higiene. Mas, quando da criaçāo da Zona Franca, surgiu a oportunidade dessa população se alocar no distrito industrial ou no agro-pecuário, passando a morar em casas de alvenaria, exercer uma profissão e melhorando, assim, sua qualidade de vida; e com isso a cidade flutuante desapareceu.

A repercussão dessas viagens nos locais era grande, tanto a nível governamental quanto a nível dos meios de comunicação. Em uma delas o então governador do Amazonas, Gilberto Mestrinho, proferiu palestra e ficou surpreso com o conhecimento dos alunos sobre os problemas da Amazônia.

De volta a São Paulo, a avaliação final era apresentada em noite especial no colégio, com áudio visual sobre toda a viagem.Um dos resultados que mais nos surpreenderam, foi a constatação, anos mais tarde, de que vários alunos, após formação universitária, voltaram a Manaus onde iniciaram sua atividade profissional.

\section{CONSIDERAÇÕES FINAIS}

Pela experiência que acabamos de descrever, acreditamos que há uma interação dos serviços turísticos na operacionalização do processo pedagógico "Estudo do Meio", possibilitando a sua maior eficácia. O Agente de Turismo e o Guia Especializado revestem-se de im- portância fundamental para tanto. Se não houver um preparo adequado de ambos, os objetivos propostos no "Estudo do Meio" não serão atingidos e as viagens viram simples excursōes.

Faz-se necessário frisar que roteiros visando o "Estudo do Meio" devem ser desenvolvidos por uma equipe multidisciplinar, tendo de um lado os professores, pedagogos e orientadores educacacionais, e de outro os profissionais de turismo.

O estudo do meio como processo educativo é uma das mais eficazes formas de ensino-aprendizagem, pois permite o contato de 24 horas aluno-aluno e aluno-professor, proporcionando vivências reais altamente proveitosas para mudanças comportamentais. No entanto, é um processo complexo, para cuja aplicação a preparação do elemento humano é primordial - todos os detalhes devem convergir para os objetivos da viagem, emergindo nos momentos adequados e submergindo em outros, mantendo o tônus da mesma a fim de que esta não seja uma simples excursão de turistas despreocupados.

No caso do Roteiro da Amazônia, por exemplo, os alunos retornam com uma concepção de ecologia, ecossistema e binômio rio-floresta tão viva e realista que não há imprensa - falada, escrita ou televisionada - que consiga conscientizá-los tão bem.

Vale dizer que esse processo é usado normalmente nos países desenvolvidos, que têm a educação como atividade primordial. No Japão, por exemplo, a educação é cuidada desde a mais tenra idade. E na família que a criança aprende uma filosofia de vida em seus mínimos detalhes, "construindo" suas atitudes perante a vida. Já na escola, a religiāo é transmitida também e especialmente pela visita aos templos religiosos, que são ao mesmo tempo a tradição da "arte-de-vida" e dos movimentos históricos japoneses. Como turistas, ficamos impressionados com a quantidade de colegiais que durante todo o ano percorre os locais mais importantes do Japão.

No Brasil, alguns colégios particulares e de um certo nível vêm usando o estudo do meio para complementar a educação de seus alunos. São poucas as experiências em escolas públicas.É uma situação lamentável, pois o conhecimento adquirido através desse processo demonstra-nos o quanto a vivência das situaçōes é importante para a formação do cidadão.

Uma viagem desse tipo talvez seja para alguns o primeiro uso de uma liberdade independente de pai, mãe, escola. E, usando essa liberdade, o aluno pode desenvolver, ao máximo, sua interação com os colegas, adultos e acompanhantes, as comunidades e locais visitados, adquirindo conhecimentos a partir de situaçōes novas... 
Obviamente, temos uma problemática educacional a ser dirigida à resoluçāo de problemas básicos que afligem nossas crianças, como o abandono nas ruas, alimentaçāo, cuidados com higiene, drogas etc., sem falarmos no proprio nível de ensino e preparo dos professores. Mas isso nāo inviabiliza que o estudo do meio seja inserido em programas públicos de educaçāo, elegendo centros de interesse importantes à formação de nossas crianças, como, por exemplo, Brasília. É nesta cidade que o brasileiro pode verificar, in loco, toda a dinâmica e respeitabilidade dos três poderes (legislativo, judiciário e executivo) e o quanto sāo necessários homens realmente preparados com conhecimento real dos nossos problemas. Talvez assim possamos ajudar a solucioná-los e colocar esta naçāo na posiçāo que ela merece, por todas as suas potencialidades físicas e humanas. E o Turismo tem um grande papel na obtenção desses resultados.

\section{AGRADECIMENTOS}

Durante meus trinta anos de experiência profissional como agente de viagens, várias pessoas colaboraram para a realizaçāo de roteiros visando o "estudo do meio". Dentre elas, cito com especial carinho as que me motivaram, mais de perto, a elaboraçāo deste artigo: Madre Isabel Sofia (Colégio Dex Oseaux) e Irmā Giselda (Colégio Sion); Samuel Dominella Franco (professor do Colégio Santa Cruz) e outros professores que contribuíram para o aperfeiçoamente desta proposta; Gisela Toledo Piza, Hilda Maria de Quadros Ferreira Coelho, Maria Tereza de Lima e Maria Aparecida de Lima Vianna (Toledo Piza Empreendimentos Turísticos).

\section{BIBLIOGRAFIA}

1. ESTUdO DO MriIO. São Paulo, Toledo Piza, 1974, 36p.

2. FRANCO, Samuel Dominella. et al. Estudo ra $8^{a}$ série do Colégio Santa Cruz. Sāo Paulo, Toledo Piza, 1974.

3. ESTUDO DO ME:IO - Programas de Viagem. São Paulo. Toledo Piza, 1963. 64p.

4. MAGALDI, Silvia. Estudo

5. BOULOS, Yara. Planejaınento de currículo. São Paulo, Grupo Escolar e Escola Experimental Dr. Edmundo Carvalho, 1970. (Apostila) 